\title{
Real Estate Investment in Shaanxi Province Promotes Economic Growth Empirical evidence from eleven prefecture level cities in Shaanxi
}

\author{
Yuwei Ma, Zhili Ren \\ Shaanxi Normal University, xi'an, shaanxi province, China \\ Shaanxi Normal University, xi'an, shaanxi province, China \\ 15291072421@163.com \\ Yuwei Ma
}

Key Words: Real estate investment economic growth

\begin{abstract}
As an important part of economic growth, real estate investment is gradually becoming the backbone of the daily activities of enterprises and people. Based on the data of a prefecture level city in Shaanxi, this paper studies the relationship between real estate investment and regional economic growth.
\end{abstract}

\section{Introduction}

As the leading industry of the national economy, the real estate industry depends on the level of development of an area or country's economy, which in turn affects the economic development of the area. It promotes and restricts each other's macroeconomic development. The real estate industry has become the pillar industry of China's national economy, and its reasonable growth has important significance for the healthy development of the national economy (Liang Yunfang et al., 2006; Xu Xianchun et al., 2015).In the past 20 years, China's real estate development has gone from rapid development to adapt to the economic development process is reasonably stable, which is a clearly response in our monetary policy report.In 2016, China's monetary policy implementation reports have not only consolidated the important status of real estate in economic operation, but also put forward a new concept of prudent management and reverse cycle regulation. This is the evolution process of real estate from birth to maturity in China. It is an important understanding of the better social development of real estate industry in China.

As the cornerstone of the real estate industry in the real estate industry, real estate investment plays a very important role in the "investment, consumption, net export", the three driving wagons driving economic growth. In 2016, the investment of real estate development in Shaanxi reached 273 billion 675 million yuan, 9.15 times in 2005, 13.14\% in the investment of all fixed assets in Shaanxi Province, and occupies an important position in the economic development.

In recent years, Shaanxi has accelerated the pace of urban construction, and steadily increased the rate of urbanization. The real estate industry has gone through a golden era of rapid development. Compared with the province (city) with remarkable characteristics of the eastern export-oriented economy, under the new normal background, the task of increasing kinetic energy conversion and industrial structure adjustment is more urgent for the inland cities of the West.In order to keep the stable and healthy development of Shaanxi's economy, how to look at the relationship between real estate investment and urban economic growth, whether the stability of economic growth is too dependent on the risk of real estate investment, the relationship between the new urbanization construction and the real estate investment is not only related to the formulation and reality of industrial policy. Shi is more closely related to changing the way of economic development, improving the carrying capacity of the city and improving the welfare of the citizens.

\section{Literature review}

At present, many scholars have studied the relationship between real estate, real estate investment, and economic growth. Their research mainly focuses on three directions: First, using input-output 
models, error correction models, and production functions to measure the contribution of real estate investment to national economic growth under the premise that real estate has been determined to have an impact on economic growth. Specific size strength (Liu Hong, 2006; Liang Yunfang et al., 2006; Yan Yongtao et al., 2007; Great Condition, 2011; Li Na et al., 2012); In this way, scholars mainly consider the driving effect of two aspects, on the one hand, the development of the real estate industry on the direct economic development of the region or the country (liang yunfang et al., 2006; Shi Minjun, Li Na, Zhou Sheng lv, Yang Jing, 2012), on the other hand, the contribute of economy development is mainly through real estate to the upstream and downstream related industries such as manufacturing and construction business.(Liu Shuixing, Wang Guojun, 2004; Liu shuxing, 2004).In this research direction, there are three kinds of conclusions drawn by scholars: the first view holds that real estate investment is an important factor to stimulate economic growth, and the development of real estate has played a role in promoting economic growth (Wang Fei, Huang Manying, 2005; Liu Hongyu, 2006; Ningyan, Xu Peng, 2008; Huang Caiyun, 2016). The second view is that the rapid development of the real estate industry will have a certain inhibitory effect on economic growth. On the one hand, although there is a "inverted $U$ " relationship between real estate investment and the development of manufacturing industry, it has reached the "critical value" (Li Chang and other, 2013). Too much emphasis on the real estate economy will undoubtedly squeeze out the investment in manufacturing industry, and affect the efficiency of manufacturing resource allocation (Zhang Chuanchuan, 2015); on the other hand, real estate investment produced a certain degree of inhibition in areas such as investment demand in innovation, and scientific and technological research and development, Other than manufacturing, which is not conducive to the overall development of society (Wang Wenchun, Rong Zhao, 2014; Zhang Jie, Yang Lianxing, new husband, 2016).The third kind of viewpoint holds that the role of real estate development on economic growth is a conditional promotion. Many scholars have such ideas in their arguments, and believe that the role of real estate in promoting steady and rapid economic growth should be based on the reasonable level of real estate economic growth. Under the premise (Xu Xianchun, 2015), and if the continuous rise of the real estate economy encounters a situation in which economic growth is hindered, it will easily lead to a bank foreign exchange crisis (Collyns and Senhadji, 2002). There are also scholars who believe that a combination of total retail sales of social consumer goods, GDP, and the inclusion of inflation should be considered as a total effect (Tang Zhijun, Xu Huijun, Ba Shusong, 2010).

Second, based on the premise that there is no confirmation of whether there is a link between real estate investment and economic growth, Granger causality test Var model is used to analyze whether there is a link between real estate investment and national economy (Shen Yue et al., 2004; Pico et al. 2004; Wang Xianzhu, 2007; Ning Yi et al., 2008; Lu Juchun et al., 2008; Luo Xiaoling et al., 2012); This type of research focuses on the relationship between the real estate industry and housing investment, mortgage loans, interest rates, credit scales and other intermediate variables. The scholars under this type of research method mainly differ from the differences in the influence of real estate and economic development due to regional differences and convergence.In the direction of this study, scholars have concluded that there are roughly two categories. The first viewpoint holds that there is a two-way causal relationship between real estate investment and economic growth, and real estate investment and economic growth affect each other (Gauger and Snyder, 2003; Pico, Wu Kangping, 2004; Wang Xianzhu, 2007). For example: Pi Shun and Wu Kangping (2004) pointed out that there is a two-way causal relationship between the development of the regional real estate market and economic growth. The current information or historical information of the urban economic fundamentals has significant urban differences in explaining the housing price level. The second type of view holds that there is only one-way causality between real estate investment and economic growth (Green, 1997; Shen Yue, Liu Hongyu, 2004; Lu Juchun et al., 2008). For example, Green (1997) observed the US quarterly data and found that from 1959 to 1992, residential investment was the Granger cause of GDP growth. On the contrary, it was not established. Shen Yue and Liu Hongyu used the annual data from 1986 to 2002 in China to analyze the interactive relationship between real estate development investment and GDP by using 
cointegration analysis, impulse response function, and predictive mean square error method. They found that GDP was Granger's investment in real estate development, but the opposite was not true.

Third, the use of spatial measurement methods to study the spatial effects of real estate-related variables and economic growth among cities (Liang Yunfang et al., 2007; Huang Zhonghua et al., 2008; Lu Juchun et al., 2008; Li Chengwu et al., 2010; Chen Xiangzhou et al., 2013; Zhang Hong et al., 2014;).Under this research method, scholars generally adopt spatial econometric analysis methods. In recent years, the rapid development of foreign spatial econometrics has been widely used in the study of some economic issues (Pan Wenqing, 2011; Zhu Pingfang, 2016). For example: He Xingqiang and Wang Lixia (2008) used space panel measurement methods to examine the spatial effects of FDI location distribution in prefectural-level cities and above in 30 provinces and cities in China, and found that there are significant spatial effects among FDI in cities.

\section{The current situation of real estate investment in China}

Since the 1990s, China's real estate has ushered in unprecedented opportunities for development. In order to quickly disengage from the economic development brought about by the financial crisis in Southeast Asia, the government has stimulated domestic demand through strong support for the real estate industry, especially during the past decade. As the proportion of real estate investment in GDP has increased year by year, it has become an indispensable part of economic development. The following table 1 shows that there is a positive correlation between the real estate investment and economic growth in Shaanxi Province.

Fig. 1. Correlation coefficient of real estate investment and gross domestic product in 11 prefecture level cities of Shaanxi province (2000-2016)

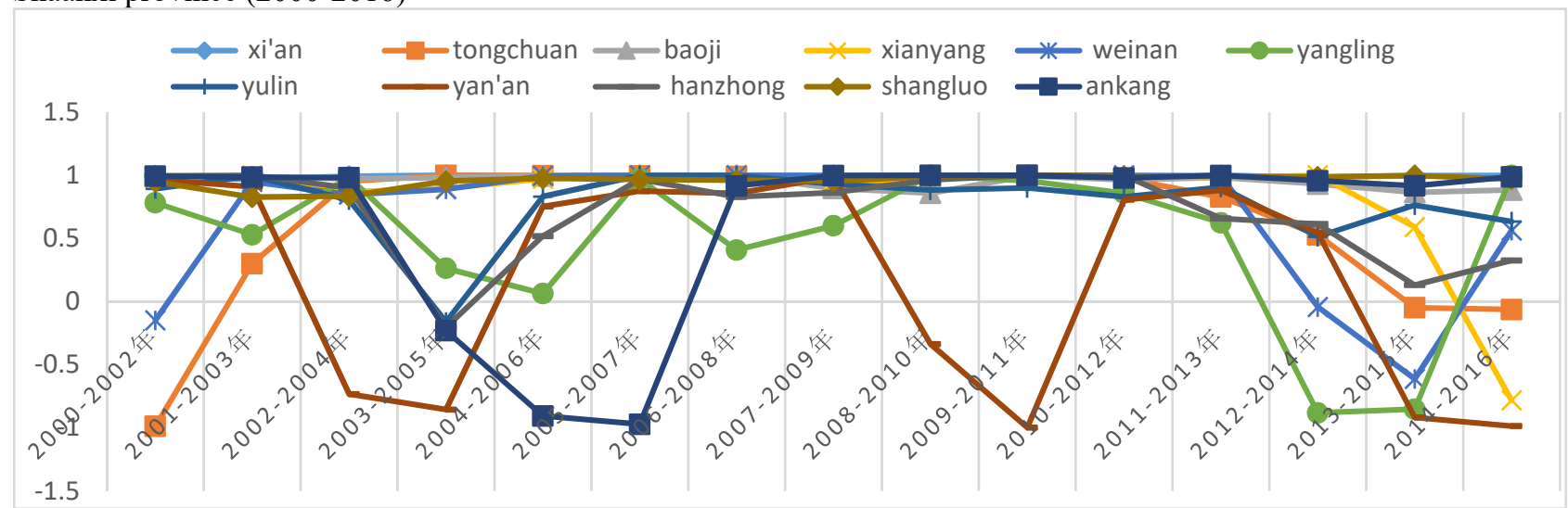

Note: Data from the Shaanxi Provincial Statistical Yearbook

\section{Theoretical basis and model}

As a classical production function, the Cobb-Douglas production function is the most widely used form of production function in economics. It has a very important position in both econometrics and mathematical economics. The production function represents the quantitative relationship between a certain combination of factors of production and the maximum output that may be obtained under certain technical conditions. This paper will analyze the real estate investment data of 11 cities in Shaanxi province and explore the contribution of real estate investment to economic growth.

Combining the characteristics of real estate investment in Shaanxi Province, the Cobb-Douglas production function is expanded to:

$$
Y_{i t}=A K_{i t}^{\alpha} L_{i t}^{\beta} R E_{i t}^{\chi} M I^{\delta}{ }_{i t}^{\delta}(1)
$$

Where $\mathrm{Y}, \mathrm{A}, \mathrm{L}, \quad \alpha, \beta$ have the same meaning, $\mathrm{K}$ represents the capital investment other than real estate investment and manufacturing investment, RE represents the real estate investment, $\chi$ represents the elasticity coefficient of real estate investment, MI represents the manufacturing investment, and $\delta$ represents The coefficient of elasticity of manufacturing investment.Use the total population POP at the end of the year to replace the labor L, $\beta$ represents the elasticity 
coefficient of the representative labor force. Take the logarithm of both sides of equation (1) to get:

$$
\ln Y_{i t}=\ln A+\alpha \ln K_{i t}+\beta \ln L_{i t}+\chi \ln R E_{i t}+\delta \ln M I_{i t}(2)
$$

First, the ADF stationary test of each variable is carried out, and the results show that all of them are first order single integer sequence, and the Johanson cointegration test is further used to show that at least one cointegration variable meets the requirements of the model.Therefore, using stata12.0 to estimate the upper model, we get the following results:

$\begin{array}{rrrr}\text { gdp } \mid & \text { Coef. } & \text { Std. Err. } & \text { P }>|\mathrm{t}| \\ \mathrm{re} \mid & .4944885 & .0484773 & 0.000 \\ \mathrm{mi} \mid & .9159406 & .0699714 & 0.000 \\ \mathrm{pop} \mid & .7133234 & .1944879 & 0.000 \\ \text { cons } \mid & 153.567 & 71.7153 & 0.034\end{array}$

R-squared $=0.8858$

It can be seen from the regression results that R-squared has reached 0.8858 , that is, the model well tested the relationship between our data. The real estate investment, manufacturing investment, the total population at the end of the year have a positive impact on the gross national product of Shaanxi province. Secondly, the manufacturing investment is the general production of the national production in Shaanxi province. The influence coefficient of value is the largest, but we should take into account the relationship between manufacturing investment and real estate investment. The real estate investment has a wide range of upstream and downstream industries. Some scholars have shown that all industries besides the garbage disposal industry have an inseparable impact on the real estate industry. Therefore, it can be seen that real estate investment contributes very significantly to economic growth. The impact of population on economic growth is also mainly reflected in the distribution of labor in various industries, so real estate investment and manufacturing investment are the main contributor to economic growth.

\section{Conclusion}

The stand or fall of real estate industry is directly related to the survival of people, with the speeding up of China's urbanization process and the continuous deepening of the reform of urban housing system, the government introduced a number of supporting the development of the real estate industry policy and credit policy, to promote rapid growth of real estate industry. And with the continuous growth of China and the increasing population, the real estate industry will undoubtedly develop more rapidly.Based on empirical data of 11 cities in Shanxi Province were analyzed, and once again proved the important role of real estate investment for the development of the economy, but we should rationally look at the issue, should not be excessive investment, the real estate industry from the consumption of its basic attribute. Irrational investment in real estate will make big money in other areas, and the unreasonable asset allocation will also hinder the region's economic growth, so the real estate investment reasonable moderate become the key to the development of regional economy.

\section{References}

[1] Jean Gauger and Tricia Coxwell Snyder,Residential Fixed Investment and the Macroeconomy: Has Deregulation Altered Key Relationships,Journal of Real Estate Finance and Economics, Vol.27(3),pp.335-354, 2003.

[2] Jihai Yu and Lung-fei Lee,Convergence:A Spatial Dynamic Panel Data Approach,Working Paper,2009.

[3] Charles Collyns and Abdelhak Senhadji,Lending Boom,Real Estate Bubbles and The Asian Crisis,Social Science Electronic Publishing,2002. 
[4] Meen, G ,'Spatial aggregation, spatial dependence and predictability in the UK housing market', Housing Studies, Vol. 11(3), pp.345-72,1996b.

[5] Meen, G ,'Regional house prices and the ripple effect: a new interpretation', Housing Studies, Vol. 14(6), pp.733-53,1999.

[6] Kelejian,H.H.\&Prucha,I.R.Specification and Estimation of Spatial Autoregressive Models with Autoregressive and Heteroskedastic Disturbances,Working paper,University of Maryland,2007.

[7] MuellbauerJ,MurphyA.Booms and busts in the UK housing market. Economic Journal,Vol. 107(445),pp.1701-1727,1997.

[8] KennyG,Modelling the demand and supply sides of the housing market:evidence from Ireland,Economic Modelling,Vol.16(3),pp.389-409,1999.

[9] Cooper A,The Impact of Interest Rates and the Housing Market on the UK Economy,Economic Outlook, Vol.28(2),pp.10-18,2004.

[10]Iacoviello M, Consumption,House Prices and Collateral Constraints:AStructural Econometric Analysis,Journal ofHousing Economics, Vol.13(4):304-320,2004. 